\title{
Salt Freeze-Thaw Damage Characteristics of Concrete based on Computed Tomography
}

\author{
Shaojie CHEN, Jianxi REN, Yongjun SONG, Qiang LI, Jielong Sun, Yongxin CHE, Jiaxing CHEN
}

\begin{abstract}
Freeze-thaw damage and salt erosion are important factors that influence the durability of concrete. In this study, degradation laws of concrete in salt freezethaw environment were discussed from the microscopic perspective based on the 3D reconstruction of computed tomography images. A damage model based on concrete aggregate volume and porosity was constructed. Furthermore, the main causes of concrete degradation in the salt freeze-thaw environment were analyzed. Results reveal that, with the increase in salt freeze-thaw cycles, the damage of concrete intensifies gradually, and the uniaxial compressive strength declines steadily. Concrete damages have two causes, namely, changes in concrete porosity and variations in concrete aggregate volume. Damages caused by aggregate volume changes are divided into frost heaving and peeling. In accordance with the constructed damage model, the porosity of concrete materials changes slightly, whereas concrete aggregate volume varies significantly. Aggregate volume changes are the main causes of intensified concrete damages and decreased compressive strength. Research conclusions provide theoretical references to disclosing microscopic damage mechanism of concrete in the salt freeze-thaw environment.
\end{abstract}

Keywords: CT technology; concrete; damage characteristics; salt freeze-thaw cycles

\section{INTRODUCTION}

Concrete is extensively applied to industrial and civil buildings, highways, bridges, and other structures. Generally, a concrete structure can serve normally and satisfy the design requirements. Nevertheless, some concrete structures are frequently in harmful media and severe environment, thus resulting in durability problems in concrete; these problems include early degradation and performance deterioration [1]. The freeze-thaw damages may occur on concrete structures given positive and negative temperature alternations in the service environment [2]. The lowest temperature in winter in some regions can be below $-40{ }^{\circ} \mathrm{C}$, thereby inducing different degrees of freeze-thaw damages on the concrete structure. Moreover, salt erosion has been discovered in many highways, bridges, and hydraulic structures [3]. Freezethaw damages and salt erosion are factors that influence the durability of concrete. These phenomena can influence the mechanical properties and service life of concrete structures significantly [4]. Traditional studies have mainly focused on concrete degradation laws under the influences of a single factor. However, a field environment is frequently influenced by many factors. Various factors may exert a synergistic effect on concrete degradation and intensify concrete failures. Therefore, concrete damage characteristics must be studied given the coupling effect of freeze-thaw failures and salt erosion.

Presently, research on concrete and rock mainly focuses on mechanical degradation [5-8]. Relevant microscopic studies have primarily adopted scanning electron microscopy and acoustic emission testing technology [9-12]. These methods cannot analyze concrete aggregate and internal porous structures intuitively. With the generalization of computed tomography (CT) technologies [13], some scholars have studied concrete and rock microstructure using CT scan images [14-15] and have achieved satisfactory results. These research results provide a new idea for studying the internal aggregate structure and porous distribution in concrete [16]. However, many studies have analyzed the 2D scanning section results of concrete and have mainly discussed the porosity and CT value of concrete but have not explored the changes in concrete aggregate structure intensively. The internal concrete structure has complicated structures in the salt freeze-thaw environment, and disclosing the deterioration mechanism accurately by considering the porous structure alone is difficult.

Thus, the concrete structure under different salt freeze-thaw cycles was discussed on the basis of the 3D reconstruction of CT scan images. Concrete degradation laws were analyzed, and a damage model was constructed to lay the foundation for further studying the concrete damage mechanism in the salt freeze-thaw environment.

\section{STATE OF THE ART}

The freeze-thaw damages and salt erosion of concrete can influence the durability of buildings significantly. Many experts have conducted numerous studies on the durability of buildings. Sicat et al. [17] conducted an experimental study on the deformation behaviour of the concrete interfacial transition zone during freeze-thaw cycles; these authors discovered that freeze-thaw cycles do not influence aggregates significantly. The mortar deformation trend in concrete is similar to that of the concrete interfacial transition zone, and a good correlation occurs between the interfacial transition zone and the concrete cracks after the freeze-thaw cycles. Gong et al. [18] studied the mechanical properties of saturated mortar in freeze-thaw cycles. These researchers constructed a hydraulic model based on the deformation characteristics of mortar to evaluate the frost damage level of concrete materials. Hasan et al. [19] studied the mechanical properties of concrete through an experiment after the freeze-thaw cycles and constructed a frost concrete stressstrain model. These researchers found that concrete strength declines because of irreversible tensile strain caused by frost heaving. To understand the internal degradation characteristics of concrete under freeze-thaw cycles, Nili et al. [20] constructed a new internal degradation prediction model of ordinary concrete under freeze-thaw cycles through experiments and mathematical formulas. This model is an effective tool for evaluating concrete degradation behaviour. Recently, salt erosion has been detected in many highways, bridges, and hydraulic 
structures. Thus, some studies on concrete durability in the salt erosion environment have been reported. These studies have achieved certain research results. Li et al. [21] analyzed the microscopic morphology and porous structural characteristics of concrete after chlorine salt erosion and discussed the relationship between the macroproperties and micro-characteristics of concrete after chlorine salt erosion. Farnam et al. [22] analyzed concrete performance in the presence of chlorine deicer in accordance with concrete composition and found the chemical reaction of an $\mathrm{MgCl}_{2}$ solution with concrete materials. The $\mathrm{CaCl}_{2}$ produced may cause damages to concrete materials. The concrete degradation laws were analyzed from salt freeze-thaw or salt erosion.

However, concrete structures frequently serve in complicated environments, such as freeze-thaw cycles and salt erosion. Some scholars have discussed concrete damage under the coupling effect of multiple factors and achieved beneficial results. Kuosa et al. [23] studied the concrete deterioration mechanism under the coupling effect of freeze-thaw cycles and chloride penetration. These authors found that concrete with a high watercement ratio due to freeze-thaw damages has many $\mathrm{Cl}-$ migrations in response to the initiation of microcracks, but concrete with a low water-cement ratio is affected slightly. Wang et al. [24] conducted an experimental study of reactive powder concrete under the coupling effect of chloride salt erosion and freeze-thaw failures and evaluated the influences of mass damage rate, relative elasticity modulus, and compressive strength on concrete durability. Skripkiūnas et al. [25] performed a freeze-thaw cycle test of concrete specimens with different cement compositions in 3\% (mass fraction) $\mathrm{NaCl}$ solution and found that freeze-thaw cycles influence the concrete surface significantly but affect the internal concrete structure slightly. These studies have mainly discussed concrete durability under coupling effects through traditional testing approaches and have primarily focused on the macroscopic physical and mechanical properties of concrete and the chemical composition of concrete materials. Nevertheless, they have considered aggregate composition and porous structure in concrete difficult to study from the microscopic perspective.

CT technology has been applied in civil engineering with the development of test approaches. Some scholars have attempted to study concrete through CT technology. Ren et al. [26] constructed a 2D finite element model with real aggregate and concrete pores based on CT technology to simulate the nonlinear breakage of concrete materials. These researchers found that the tensile strength of concrete decreases with the increase in porosity. Henry et al. [27] conducted a non-destructive test of the microstructure of high-strength concrete using CT images and analyzed the influences of heating and re-curing on the microstructural characteristics of concrete. Some scholars have applied CT technology in concrete freeze-thaw tests. Suzuki [28] performed the CT scanning of concrete samples and observed the crack distribution on samples. They evaluated the mechanical degradation characteristics of concrete through the mean CT value. Moreover, they performed a quantitative evaluation of the damages in concrete structures. Tian et al. [29] analyzed the microscopic damages of concrete in sulfate-attacking environment using CT technology and studied the spatial distribution and evolutionary laws of the internal porous structure of concrete based on 3D reconstruction technology. These researchers proposed a microscopic damage mechanism of concrete based on porous zoning. These studies have mainly analyzed the pore distribution of concrete based on 2D scanning images, but few have discussed the concrete damage characteristics under salt freeze-thaw conditions. Therefore, the concrete damages under different salt freeze-thaw cycles were discussed on the basis of the $3 \mathrm{D}$ reconstruction of CT scan images. The variation laws of concrete aggregate volume and porosity were analyzed. A damage model was constructed. The research conclusions laid the foundation for further studying the concrete damage mechanism in the salt freeze-thaw environment.

The remainder of this paper is organized as follows. Section 3 introduces the salt freeze-thaw experiment of concrete. Section 4 analyzes the variation laws of concrete volume, porosity, and CT value under the salt freeze--thaw effects. The concrete damage model constructed under different salt freeze-thaw conditions is discussed. Section 5 presents the conclusions drawn from this study.

\section{METHODOLOGY}

\subsection{Test Materials and Design}

A 42.5-grade ordinary Portland cement made by Jidong Cement Tongchuan Co., Ltd., was utilized in the experiment. The physical and mechanical properties of the 42.5-grade ordinary Portland cement are listed in Table 1. The coarse aggregate used stones from Hua County, Shaanxi Province. The grain composition, apparent density, bulk density, and crush index of the coarse aggregate were 5-20 mm, $2750 \mathrm{~kg} / \mathrm{m}^{3}, 1510 \mathrm{~kg} / \mathrm{m}^{3}$, and $6 \%$, correspondingly. The fine aggregate applied sands from the Ba River. The apparent density, bulk density, and fineness modulus of the fine aggregate were $2630 \mathrm{~kg} / \mathrm{m}^{3}$, $1480 \mathrm{~kg} / \mathrm{m}^{3}$, and 2.7 , respectively.

Here, 10 groups of $27100 \mathrm{~mm} \times 100 \mathrm{~mm} \times 100 \mathrm{~mm}$ cubic samples were prepared. One group was used for the CT scan test under the same conditions. Water-cement ratio of concrete samples was 0.55 . The cement, sand, stone, and water contents were 364, 670, 1240, and 200 $\mathrm{kg} / \mathrm{m}^{3}$, correspondingly. After 24 hours' concrete pouring, the forms were removed and the natural curing was carried out on the concrete samples. Then the freeze-thaw test began after 60 days' curing. The comprehensive strengths of the concrete samples at 7 and 28 days were 18.8 and 32.6 $\mathrm{MPa}$, respectively.

\subsection{Experimental Apparatus and Schemes}

The fast KDR-V9 concrete freeze-thaw machine made by Beijing Digital Intelligence Yilong Instrument Company was utilized. The freeze-thaw experiment was performed through the fast-freezing method in the Test Standards for Long-term Performance and Durability of Ordinary Concrete GB/T50082-2009 [30] (Fig. 1). Prior to the experiment, concrete samples were immersed in $5 \%$ $\mathrm{NaCl}$ solution for 4 days. Then, the freeze-thaw experiment was conducted after the saturation of all samples. The lowest and highest temperatures in the center 
of the samples were controlled at $(-18 \pm 2){ }^{\circ} \mathrm{C}$ and $(5 \pm$ 2) ${ }^{\circ} \mathrm{C}$, correspondingly. Each freeze-thaw cycle was accomplished in 2-4 h, and a group of 3 concrete samples was collected every 25 freeze-thaw cycles to test the uniaxial compressive strength. One group of concrete samples was designed under the same conditions. All samples were used for the CT scan test after each freezethaw cycle.

Table 1 Physical and mechanical properties of cement

\begin{tabular}{|c|c|c|c|c|c|c|c|c|c|c|c|}
\hline \multirow{2}{*}{ Setting time } & \multirow{2}{*}{$\begin{array}{l}\text { Density } \\
\left(\mathrm{g} / \mathrm{cm}^{3}\right)\end{array}$} & \multirow{2}{*}{$\begin{array}{c}\text { Specific } \\
\text { surface area } \\
\left(\mathrm{m}^{2} / \mathrm{kg}\right)\end{array}$} & \multirow{2}{*}{$\begin{array}{c}\text { Water } \\
\text { requirement of } \\
\text { normal } \\
\text { consistency }(\%)\end{array}$} & \multicolumn{2}{|c|}{$\begin{array}{c}\text { Flexural strength } \\
(\mathrm{MPa})\end{array}$} & \multicolumn{2}{|c|}{$\begin{array}{c}\text { Compressive } \\
\text { strength }(\mathrm{MPa}) \\
\end{array}$} & \multirow{2}{*}{$\begin{array}{l}\mathrm{SO}_{3} \\
(\%)\end{array}$} & \multirow{2}{*}{$\begin{array}{c}\mathrm{MgO} \\
(\%)\end{array}$} & \multirow{2}{*}{$\begin{array}{l}\text { Loss on } \\
\text { ignition } \\
(\%)\end{array}$} & \multirow{2}{*}{$\begin{array}{c}\mathrm{Cl} \\
(\%)\end{array}$} \\
\hline & & & & $3 d$ & $28 \mathrm{~d}$ & $3 d$ & $28 \mathrm{~d}$ & & & & \\
\hline $\begin{array}{l}\text { Initial setting time } 65 \mathrm{~min} \\
\text { Final setting time } 260 \mathrm{~min}\end{array}$ & 3.05 & 358 & 28.8 & 5.6 & 8.6 & 29.5 & 51.0 & 2.5 & 1.3 & 4.6 & 0.02 \\
\hline
\end{tabular}

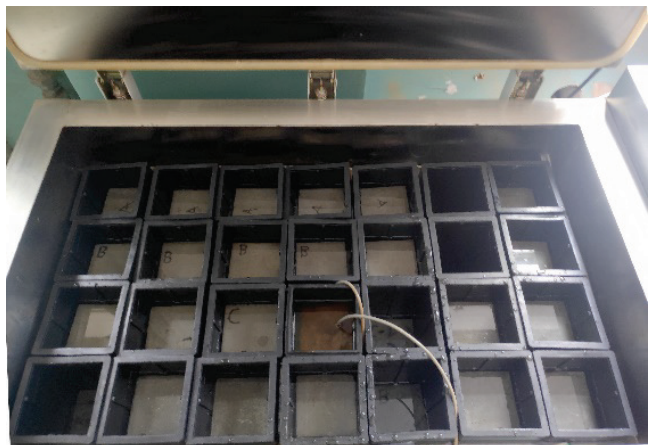

Figure 1 Freeze-thaw test

The Brilliance iCT 256-layer spiral top-speed CT machine made by Philips was used in the CT scan test. The following scanning parameters were set: $120 \mathrm{kV}$ of voltage and $117 \mathrm{~mA}$ of current. The slice thickness was set to $1 \mathrm{~mm}$. The cubic concrete samples were scanned continuously under saturation conditions along the cross section, and the display matrix was $512 \times 512$. All concrete samples were wrapped using a thin film to prevent the liquid evaporation of samples. The scanning test is depicted in Fig. 2.

The uniaxial compressive test was performed on the concrete samples using the TYA-2000 compression machine after finishing the salt freeze-thaw test. Loads were applied at the rate of $5 \mathrm{kN} / \mathrm{s}$ through axial force control until the failure of samples. The mean of the three samples in one group was used as the compressive strength.

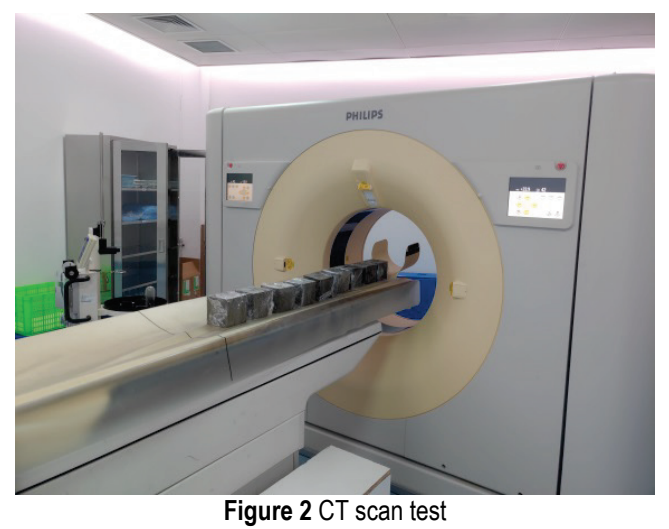

\subsection{Principle of CT Technology}

CT technology is a special technology that quantitatively describes the tomography of the testing object based on a computer and determines the compactness of substances in accordance with the X-ray attenuation degree of the testing object, thus disclosing the internal structure through inversion. Different materials show various X-ray attenuation degrees. After one X-ray beam penetrates the testing substances, the attenuation law can be expressed as [31].

$I=I_{0} \exp \left[-d\left(\mu_{1}+\mu_{2}+\cdots+\mu_{i}+\cdots\right)\right]$

where $I$ is the $\mathrm{X}$-ray strength after passing through substances, $I_{0}$ is the initial incidence strength of the X-ray, $\mu_{i}$ is the attenuation coefficient of rays after passing through different materials, and $d$ is the unit length of the testing materials.

During actual scanning, the testing materials are divided into $m \times n$ voxel units, thus producing $m \times n \quad I$ values. CT images composed of $m \times n$ attenuation coefficients were obtained from the reconstruction of computer images.

The relative value of each pixel was determined after the reconstruction of the CT scan data, and the compactness of the testing materials could be expressed as CT values [32] by normalizing the linear attenuation coefficient relative to water.

$H=1000 \times \frac{\mu-\mu_{w}}{\mu_{w}}$

where $H$ is the $\mathrm{CT}$ value of the testing materials $(\mathrm{Hu}), \mu$ is the attenuation coefficient of the testing materials, and $\mu_{w}$ is the attenuation coefficient of water.

In this experiment, concrete, which is a composite, was used as the testing material. The CT values were the means of the components. The CT scan images were the crosssection diagrams of the concrete samples and piled up layer by layer to construct a complete $3 \mathrm{D}$ model of the concrete samples.

\section{RESULT ANALYSIS AND DISCUSSION}

In this study, CT scanning data were processed and analyzed by VG Studio Max. Concrete microstructural changes under different salt freeze-thaw cycles were analyzed through 2D scanning section and 3D reconstruction technology. Given the limited article space, one concrete sample was presented in the $2 \mathrm{D}$ section and $3 \mathrm{D}$ reconstruction analyses.

\subsection{CT Scanning Results of Concrete in the Salt Freeze- Thaw Environment}

The 2D sectional images of concrete at 20, 40, 60, and $80 \mathrm{~mm}$ heights were analyzed to study the microscopic 
damages of concrete under different salt freeze-thaw cycles (Fig. 3).

The sectional images under $0,50,100,150$, and 200 salt freeze-thaw cycles were chosen and analyzed. The sectional area of concrete was changed after the salt freeze-thaw cycles. For the contrast analysis of parameter changes after the salt freeze-thaw cycles, a $105 \times 105 \times 1$ $\mathrm{mm}$ space unit range was selected for the extraction of sections (Fig. 4).

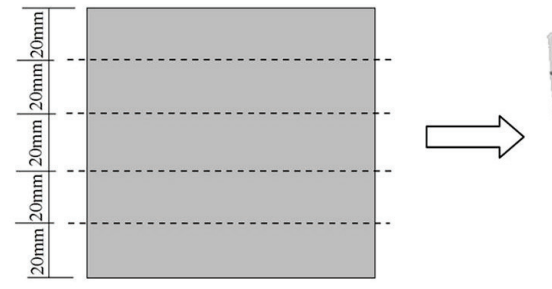

Figure 3 Scanning sections

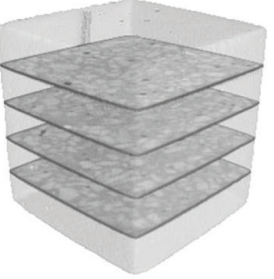

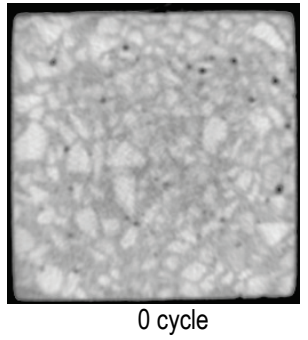

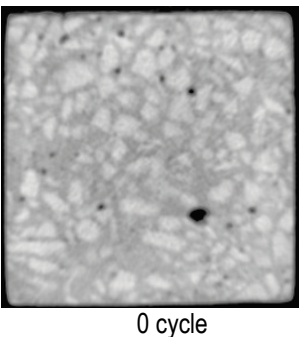

cycle
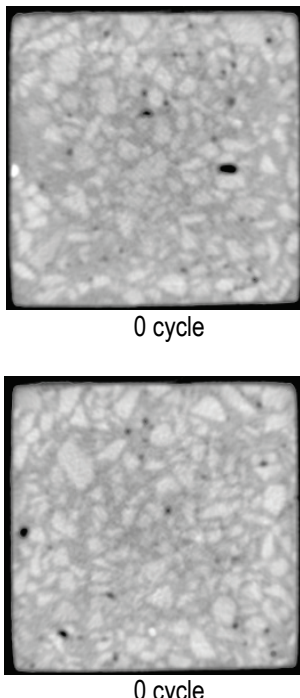
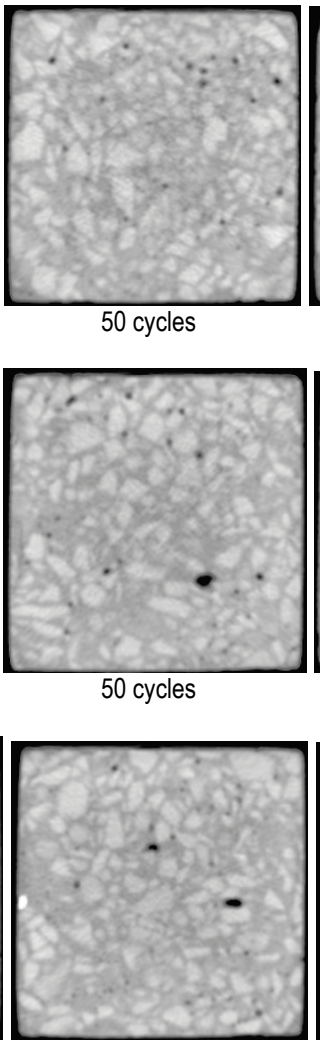

50 cycles

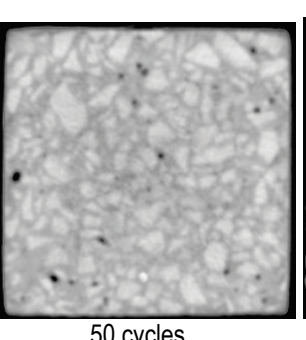

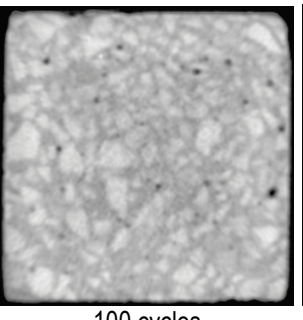

100 cycles

(a) $20 \mathrm{~mm}$ section

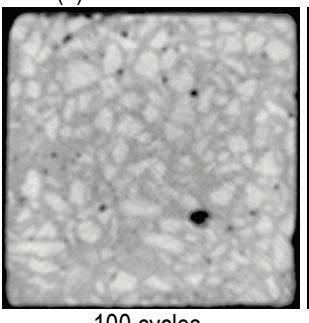

100 cycles

(b) $40 \mathrm{~mm}$ section

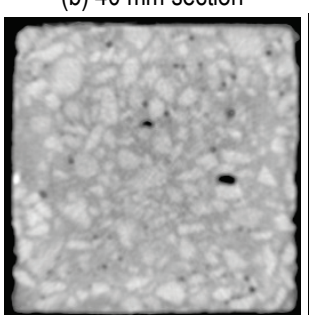

100 cycles

(c) $60 \mathrm{~mm}$ section

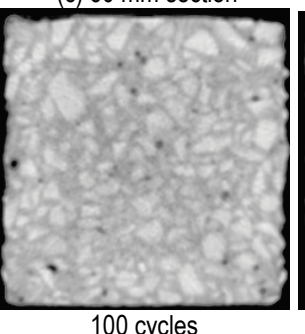

(d) $80 \mathrm{~mm}$ section
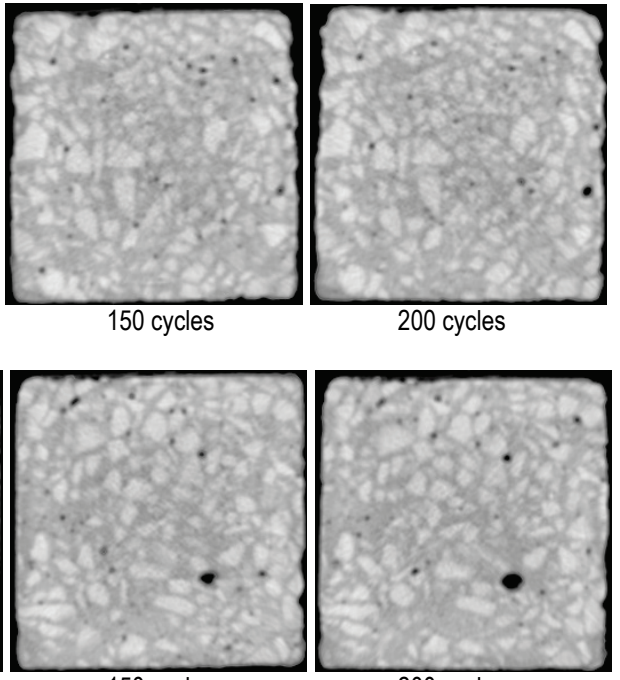

150 cycles

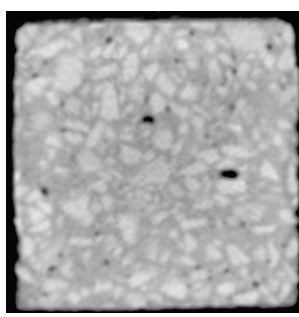

150 cycles

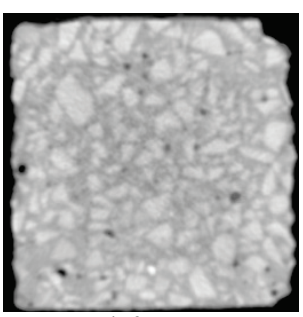

150 cycles

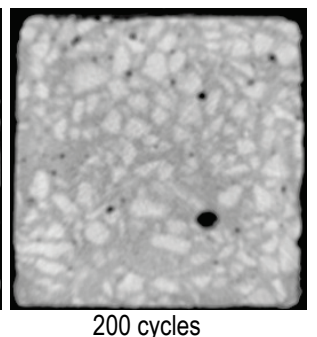

200 cycles

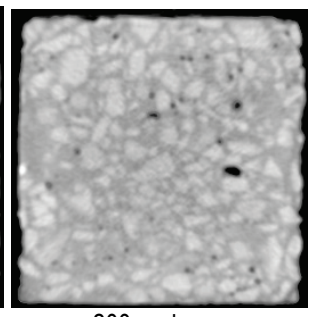

200 cycles

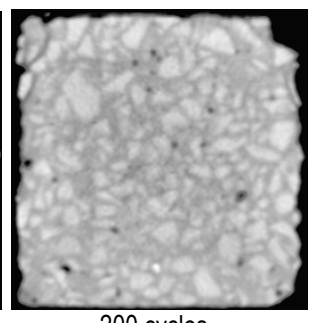

200 cycles

Figure $4 \mathrm{CT}$ images of sections under different salt freeze-thaw cycles

The aggregate distribution and internal pores on different sections of the concrete samples can be observed in Fig. 4. With the increase in the salt freeze-thaw cycles, the external concrete on different sections peels off to different extents, whereas the internal pores change slightly. The relative CT values and volumes of different sections were analyzed (Figs. 5 and 6).

The CT value can reflect the compactness of materials. The CT value of all materials in the chosen region is demonstrated in Fig. 5. These materials are composed of concrete materials, while $\mathrm{NaCl}$ solution filled in the concrete and surrounding air. In accordance with Equation (2), the relative CT value can be expressed as

$$
H_{a(i)}=\frac{H_{c(i)} V_{c(i)}+H_{l(i)} V_{l(i)}+H_{g(i)} V_{g(i)}}{V}
$$

where $H_{a(i)}$ is the relative CT value in the selected region at salt freeze-thaw cycle $i(\mathrm{Hu}) . H_{c(i)}$ is the CT value of the concrete aggregate at salt freeze-thaw cycle $i(\mathrm{Hu})$. $H_{l(i)}$ is the CT value of the $\mathrm{NaCl}$ solution in the concrete samples at salt freeze-thaw cycle $i(\mathrm{Hu}) . H_{g(i)}$ is the CT value of gas in the chosen region at salt freeze-thaw cycle $i(\mathrm{Hu}) . V_{c(i)}$ is the concrete aggregate volume at salt freeze-thaw cycle $i\left(\mathrm{~mm}^{3}\right) . V_{l(i)}$ is the volume of the $\mathrm{NaCl}$ 
solution in the concrete samples at salt freeze-thaw cycle $i$ $\left(\mathrm{mm}^{3}\right) . V_{g(i)}$ is the volume of gas in the selected region at salt freeze-thaw cycle $i\left(\mathrm{~mm}^{3}\right) . V$ is the total volume of the chosen region $\left(\mathrm{mm}^{3}\right)$.

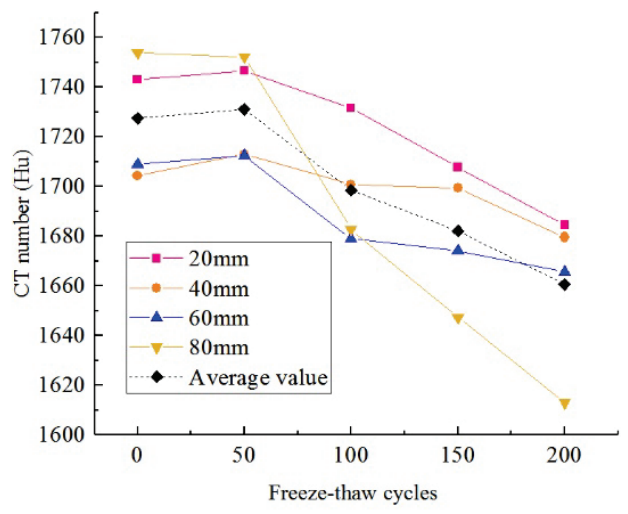

Figure 5 Relation between relative CT values of different scanning sections and salt freeze-thaw cycles

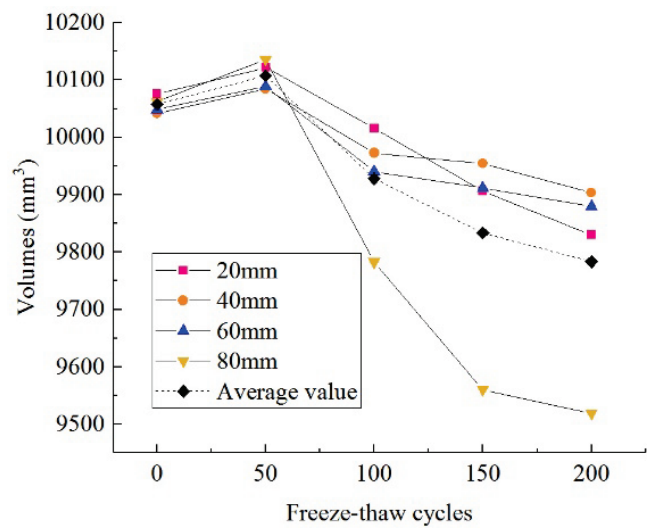

Figure 6 Relation between the volume of different scanning sections and salt freeze-thaw cycles

Microcracks develop on concrete materials in the early stage of freeze-thaw cycles, accompanied with the increase in the overall volume of samples. The cracks were all filled and saturated by the $\mathrm{NaCl}$ solution. Given that the components of concrete materials will not be increased, if $V_{c}$ is constant, and $V_{l}$ increases, then $V_{g}$ decreases. The $\mathrm{CT}$ value of the selected region can be expressed as

$H_{a(i)}=\frac{H_{c(i-n)} V_{c(i-n)}+H_{l(i-n)}\left(V_{l(i-n)}+\Delta V\right)+H_{g(i-n)}\left(V_{g(i-n)}-\Delta V\right)}{V}(4)$

$\Delta V=V_{c(i)}-V_{c(i-n)}$

where $H_{c(i-n)}$ is the relative CT value of the concrete aggregate at salt freeze-thaw cycle $i-n(\mathrm{Hu}) . H_{l(i-n)}$ is the $\mathrm{CT}$ value of the $\mathrm{NaCl}$ solution in the concrete samples at salt freeze-thaw cycle $i-n(\mathrm{Hu}) . H_{g(i-n)}$ is the CT value of gas in the chosen region at salt freeze-thaw cycle $i-n(\mathrm{Hu}) . V_{c(i-n)}$ is the concrete aggregate volume at salt freeze-thaw cycle $i-n\left(\mathrm{~mm}^{3}\right) . V_{l(i-n)}$ is the volume of the $\mathrm{NaCl}$ solution in the concrete samples at salt freezethaw cycle $i-n\left(\mathrm{~mm}^{3}\right) . V_{g(i-n)}$ is the volume of gas in the selected region at salt freeze-thaw cycle $i-n\left(\mathrm{~mm}^{3}\right) . n$ is the salt freeze-thaw cycles. $\Delta V$ is the changes in the volume of the samples $\left(\mathrm{mm}^{3}\right)$.

Figs. 5 and 6 exhibit that the relative CT value of the sections of the samples increases initially and then decreases with the increase in salt freeze-thaw cycles. The $80 \mathrm{~mm}$ scanning section shows the largest area losses, followed by the 20,60 , and $40 \mathrm{~mm}$ scanning sections successively. This result reflects that the peeling loss of the samples at the two ends is higher in the salt freeze-thaw environment than in the middle region. Micropores and fine aggregates develop volume expansion given frost heaving in the early stage of the salt freeze-thaw cycles. The internal structure is loose, and the sample volume increases. Equation (4) expresses that the surrounding solution fills in cracks in concrete materials during melting. The CT value of the solution is approximately $71 \mathrm{Hu}$, which is smaller than that of concrete materials but higher than that of air $(-1000 \mathrm{Hu})$. Thus, the relative CT value in the chosen region increased. The concrete surface material peeled off after 100 freeze-thaw cycles, accompanied by the reduction of the surface area. In the selected $105 \mathrm{~mm} \times$ $105 \mathrm{~mm}$ space, the original concrete material was replaced by air. The relative CT value declined because the CT value was far lower in air than in the materials.

\subsection{D Reconstruction Results Analysis of Concrete in the Salt Freeze-Thaw Environment}

With the increase in salt freeze-thaw cycles, concrete develops different degrees of damages. The apparent changes are displayed in Fig. 7. The 3D reconstruction of the CT data of concrete samples could be realized with 3D reconstruction software (Fig. 8). To extract the internal porous and aggregate structures in concrete, aggregate and porous structures were distinguished through the threshold range in the $3 \mathrm{D}$ reconstruction. The threshold ranges of different materials were determined through the preprocessing of CT image data. The CT value of images ranged from $-1024 \mathrm{Hu}$ to $3701 \mathrm{Hu}$, and the threshold range of pores was set to $-1024-1250 \mathrm{Hu}$. The porous structure is illustrated in Fig. 9. The threshold range of concrete materials, fine aggregate, and coarse aggregate were 12513701, 1251-1900, and 1901-3701 Hu, respectively. The 2D sections and 3D reconstruction morphology are depicted in Figs. 10 and 11.

The concrete appearances after 0,100 , and 200 salt freeze-thaw cycles are demonstrated in Fig. 7. Serious surface peeling damages could be observed on the concrete in the salt freeze-thaw environment, accompanied by the gradual exposure of coarse aggregates and some stone falling. The 3D reconstruction diagram (Fig. 8) reflects the external damage characteristics of the samples accurately.

The porous structure distribution in the concrete samples is exhibited in Fig. 9. The maximum pore volume at 0 salt freeze-thaw cycle was $194.85 \mathrm{~mm}^{3}$, which decreased to $192.57 \mathrm{~mm}^{3}$ at 100 salt freeze-thaw cycles and increased to $200.81 \mathrm{~mm}^{3}$ again at 200 salt freeze-thaw cycles. That is, the maximum pore volume in the concrete samples decreased slightly in the early stage of the salt freeze-thaw cycles and then increased in the late stage.

The statistics on the total number of pores are plotted in Fig. 12. The total number of pores decreased initially 
and then increased with the salt freeze-thaw cycles but presents a generally decreasing trend. The reduction in the total number of pores in the early stage of the salt freezethaw cycles was due to two phenomena. On the one hand, the concrete surface peeled off, and external pores decreased due to frost heaving. On the other hand, some pores were connected given the salt freeze-thaw cycles, thus decreasing the total number of pores. The total number of pores in the late stage of the salt freeze-thaw cycles increased slightly in response to the loose aggregate structure of concrete and increased the number of pores. Given that peeling damage takes a dominant role, the total number of pores decreased gradually.

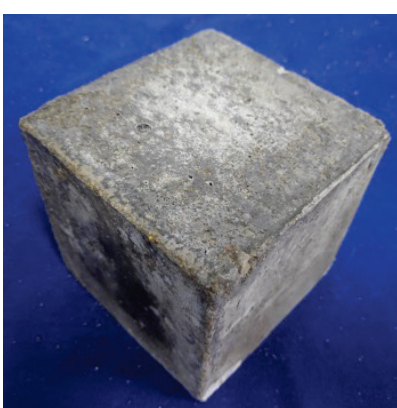

(a) 0 cycle

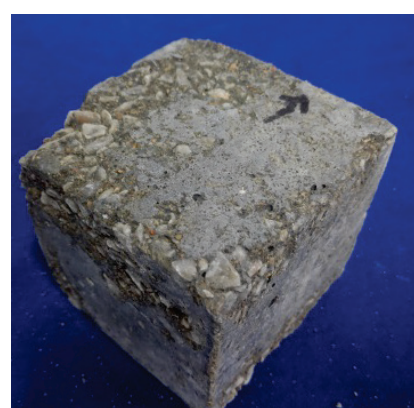

(b) 100 cycles

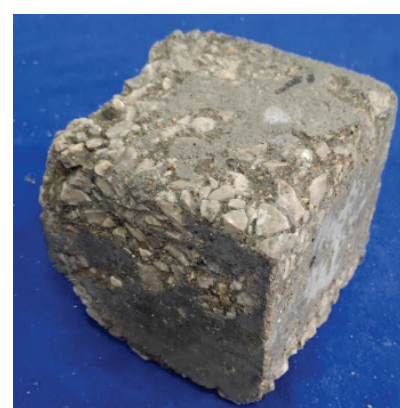

(c) 200 cycles

Figure 7 Concrete appearance after salt freeze-thaw

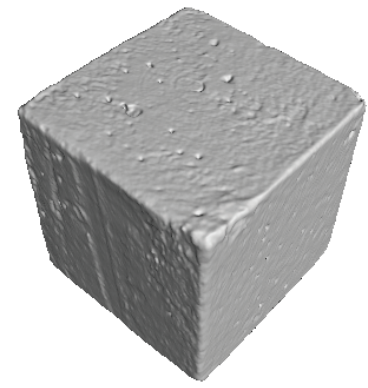

(a) 0 cycle

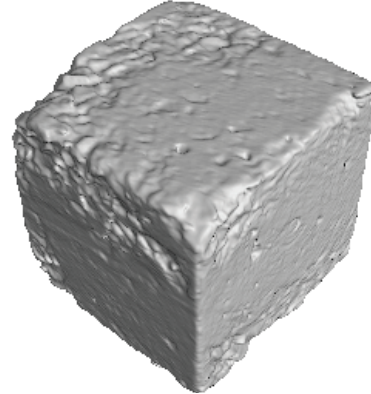

(b) 100 cycles

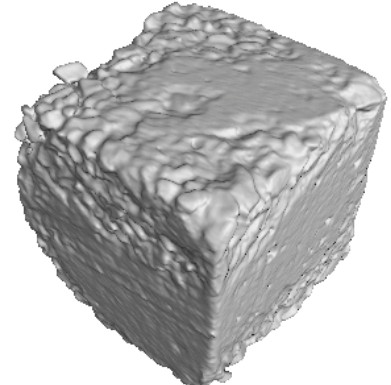

(c) 200 cycles

Figure 8 3D reconstruction appearance of concrete samples

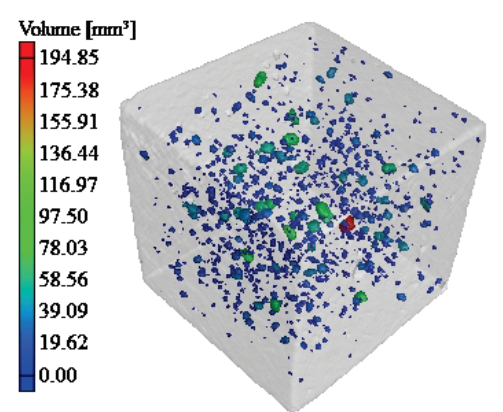

(a) 0 cycle

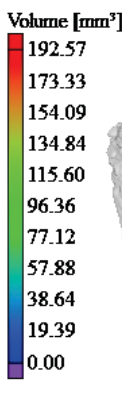

(b) 100 cycles

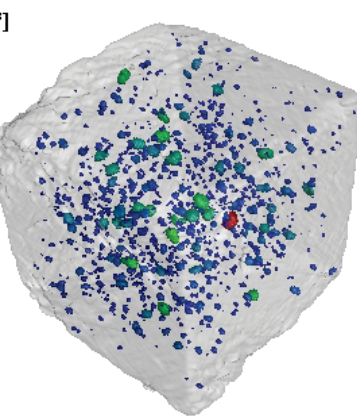

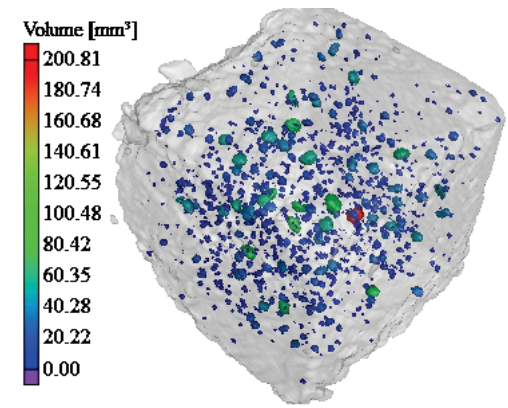

(c) 200 cycles

Figure 9 Pore distribution of concrete samples

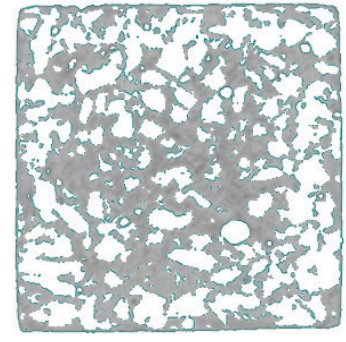

$\begin{array}{ll}\begin{array}{ll}\text { (a) 2D section } & \text { (b) 3D reconstruction map }\end{array} & \\ \text { Figure } 10 \text { Reconstruction diagram of fine aggregate }\end{array}$

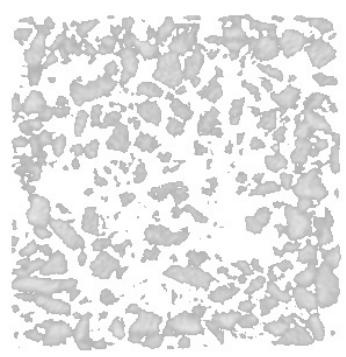

(a) 2D section

(b) 3D reconstruction map

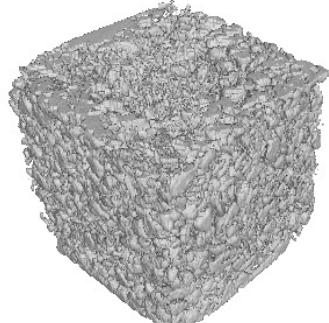

diagram of coarse aggregate 


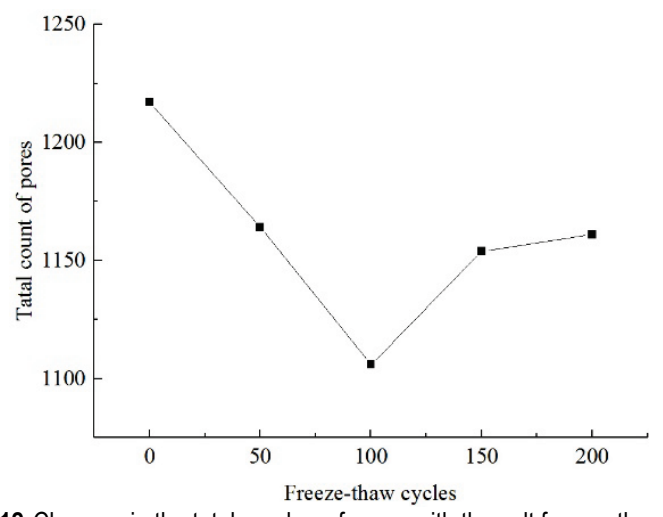

Figure 12 Changes in the total number of pores with the salt freeze-thaw cycles

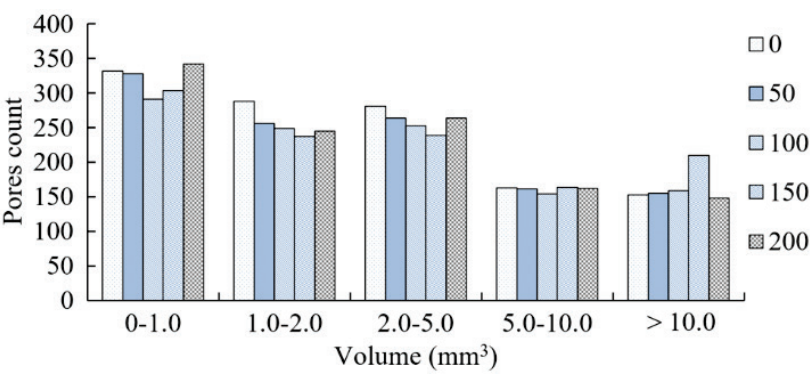

Figure 13 Changes in the pore volume with the salt freeze-thaw cycles

The changes in pore volume with the salt freeze-thaw cycles are displayed in Fig. 13. The number of small pores $\left(0-1.0 \mathrm{~mm}^{3}\right)$ accounted for a high proportion and decreased initially and then increased with the salt freeze-thaw cycles. This result reveals that small pores connect in the early stage of the salt freeze-thaw cycles, thus decreasing the total number of pores. The total number of pores increased in the late stage given the initiation of new small pores. The number of pores $\left(1.0-5.0 \mathrm{~mm}^{3}\right)$ decreased continuously before 150 salt freeze-thaw cycles and increased slightly at the 200th salt freeze-thaw cycle. The number of pores $\left(5.0-10.0 \mathrm{~mm}^{3}\right)$ changed slightly, thereby indicating that the number pores in this volume range is slightly sensitive to salt freeze-thaw cycles. Large pores $\left(>10.0 \mathrm{~mm}^{3}\right)$ increased before 150 salt freeze-thaw cycles, but decreased at 200 salt freeze-thaw cycles. This outcome implies that some small pores developed into large pores during the salt freeze-thaw cycles, and some large pores disappeared in the late stage given the peeling of concrete aggregate. Therefore, the number of large pores decreased.
The changes in the concrete aggregate volume and porosity of the samples with the salt freeze-thaw cycles are presented in Fig. 14. In the early stage of the salt freezethaw cycles, the aggregate volume increased. This result is the collaborative consequence of the internal structural expansion given frost heaving and few surface peeling damages. The peeling of surface aggregates accelerated after 50 salt freeze-thaw cycles, and volume decreased accordingly. The volume loss rate at 200 salt freeze-thaw cycles was approximately $4.5 \%$. The porosity of the concrete samples was between $0.66 \%$ and $0.69 \%$. It fluctuated with the increase in salt freeze-thaw cycles and increased slightly in the late stage. However, the overall change was small, thus indicating that salt freeze-thaw cycles are mainly caused by the peeling of concrete aggregates.

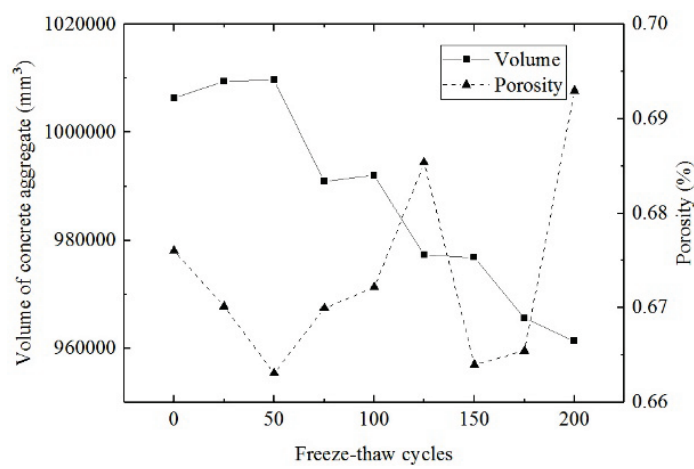

Figure 14 Changes in the concrete aggregate volume and porosity of the samples with the salt freeze-thaw cycles

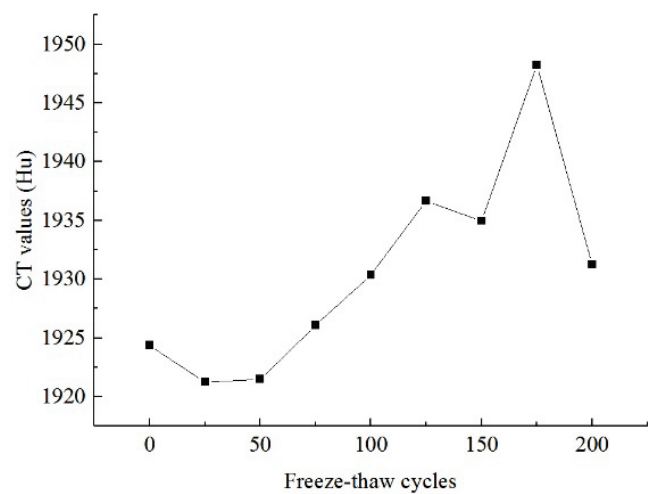

Figure 15 Changes in the CT value of the concrete aggregate with the salt freeze-thaw cycles

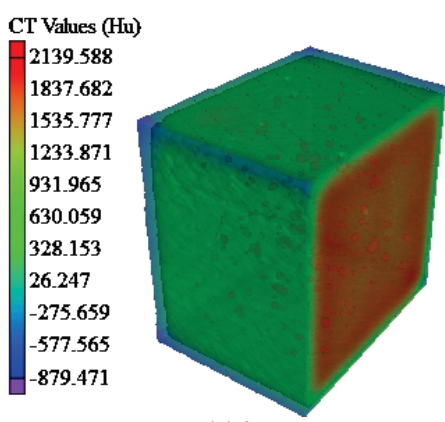

(a) 0 cycle

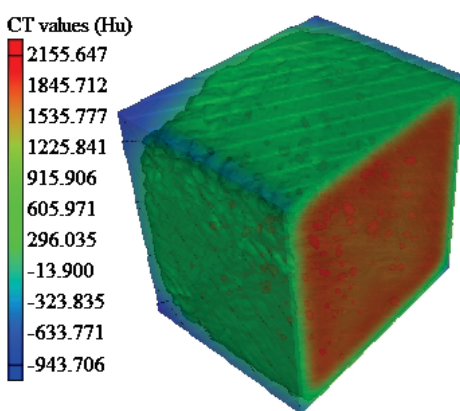

(b) 100 cycles

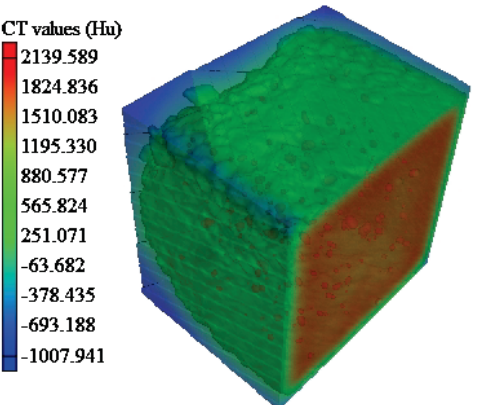

(c) 200 cycles

Figure 16 Distribution of CT values of concrete samples

The changes in the CT value of the concrete aggregate with salt freeze-thaw cycles are illustrated in Fig. 15. No monotonous increasing or decreasing relationship was observed between the CT value of the aggregate and the salt freeze-thaw cycles. The CT value of the aggregate decreased initially and then increased and began to 
fluctuate since the 100th salt freeze-thaw cycle. The reduction in the $\mathrm{CT}$ value in the early stage was mainly due to the increased volume and low compactness given the loose internal structure. The increased $\mathrm{CT}$ value of the aggregate during the 50th-125th salt freeze-thaw cycle was due to the peeled materials in the early stage were caused by cement mortar. Given that the CT value was smaller in fine aggregate than in coarse aggregate, the mean CT value increased. The fluctuation in the $\mathrm{CT}$ value after 125 salt freeze-thaw cycles was mainly due to the peeling of the coarse aggregates outside the concrete samples in the late stage. This phenomenon was manifested by the fine-coarse aggregate alternative losses. Thus, the mean CT value of the concrete materials fluctuated.

The distribution of the CT value of the concrete samples is depicted in Fig. 16. To disclose the situations in the cross section of concrete, $3 \mathrm{D}$ images were cut inward along the surface by $15 \mathrm{~mm}$. Clearly, the region with the highest $\mathrm{CT}$ value of the chosen cubic concrete samples is in the concrete materials, and the CT value is smaller on the material surface than in the materials.

\subsection{Concrete Damage Analysis in the Salt Freeze-Thaw Environment}

Concrete damages refer to the deterioration process caused by internal material defects under the influences of environment or loads. Thus, concrete damages under salt freeze-thaw cycles can be called salt freeze-thaw damages. Some scholars have constructed a damage model based on freeze-thaw cycles and concrete porosity by considering porosity a damage variable. According to previous analysis results, the porosity of concrete materials changes slightly in salt freeze-thaw cycles, whereas the volume of concrete aggregate changes significantly. Therefore, the damages of concrete materials cannot be evaluated when only porosity is considered. For further intensive analysis of the concrete damages under salt freeze-thaw cycles, concrete aggregate volume and porosity were used as evaluation indexes in constructing a damage model.

Based on previous analysis, the concrete aggregate volume did not present a monotonous increase with the salt freeze-thaw cycles. The damage process is divided into two parts, namely, frost heaving damages manifested by volume expansion and aggregate peeling damage manifested by volume shrinkage. Therefore, volume expansion or shrinkage is manifested by intensified damages when volume is used as a damage variable. The change rate of the aggregate volume can be used to express the increase in damages caused by volume changes.

$$
D_{V(i)}=\frac{\left|V_{c(i)}-V_{c(i-n)}\right|}{V_{c(i-n)}} \times 100 \%
$$

where $D_{V(i)}$ is the increase in damages caused by aggregate volume changes at salt freeze-thaw cycle $i$. The increment at the initial state is 0 .

Porosity is an important index for evaluating material damages. Material damage is intensified with the increase in material porosity but is relieved upon the reduction of porosity. Thus, the change in the values of porosity can be used to express the increase in damages caused by pores. If the increase is positive, then the increase in porosity may intensify the damages. If the increase is negative, then the reduction in porosity relieves the damages.

$D_{P(i)}=\frac{P_{i}-P_{i-n}}{P_{i-n}}$

where $D_{P(i)}$ is the increase in damages caused by porosity changes at salt freeze-thaw cycle $i . P_{i-n}$ is the porosity of the samples at salt freeze-thaw cycle $i-n . P_{i}$ is the porosity of the samples at salt freeze-thaw cycle $i$.

With the comprehensive consideration of the influences of aggregate volume and porosity changes, the increase in damages of concrete samples at salt freezethaw cycle $i$ in comparison with those at salt freeze-thaw cycle $i-n$ can be expressed as

$\Delta D_{(i)}=D_{V(i)}+D_{P(i)}$

where $\Delta D_{(i)}$ is the increase in damages of the concrete samples at salt freeze-thaw cycle $i$ in comparison with those at salt freeze-thaw cycle $i-n$.

The degree of concrete damage under different salt freeze-thaw cycles can be expressed by accumulative increase in damages.

$D=\sum_{0}^{i} \Delta D_{(i)}$

where $D$ is the degree of concrete damage at salt freezethaw cycle $i$.

In Equation (9), the initial degree of damage is equal to the initial porosity of concrete. In the calculation, the mean CT scanning results of the three samples in the same batch was selected. The changes in the mean degree of damages and the mean uniaxial compressive strength of the samples with the salt freeze-thaw cycles are summarized in Table 2.

Table 2 Degree of damages and compressive strength of samples under different salt freeze-thaw cycles

\begin{tabular}{|c|c|c|}
\hline $\begin{array}{c}\text { Freeze-thaw } \\
\text { cycles }\end{array}$ & $\begin{array}{c}\text { Average damage } \\
(\%)\end{array}$ & $\begin{array}{c}\text { Compressive strength } \\
(\mathrm{MPa})\end{array}$ \\
\hline 0 & 0.54 & 39.05 \\
\hline 25 & 0.72 & 38.70 \\
\hline 50 & 0.84 & 36.13 \\
\hline 75 & 1.82 & 34.70 \\
\hline 100 & 2.03 & 34.50 \\
\hline 125 & 2.84 & 33.77 \\
\hline 150 & 3.37 & 32.53 \\
\hline 175 & 4.43 & 30.33 \\
\hline 200 & 8.93 & 27.00 \\
\hline
\end{tabular}

Table 2 displays that concrete damages are intensified with the increase in salt freeze-thaw cycles, whereas the uniaxial compressive strength decreases. The fitting map of freeze-thaw cycles and the degree of damages are exhibited in Fig. 17. The fitting results show an exponential 
distribution of the degree of concrete damage with the freeze-thaw cycles.

$$
D=0.5255 e^{0.0132 i}
$$

According to the fitting results, the slope of the concrete damage curve in the early stage increases slowly, thus indicating a small degree of concrete damages. However, the slope increases quickly after 100 freezethaw cycles, thereby implying that the concrete aggregate peels significantly in this stage. Crack development accelerates, and the degree of damages increases.

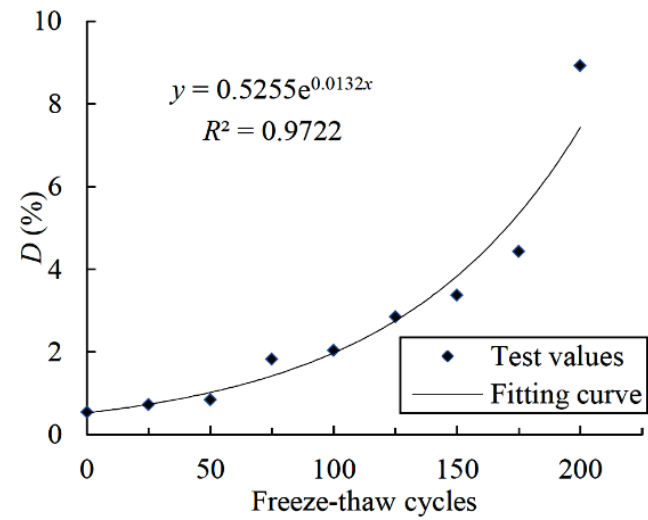

Figure 17 Relationship between salt freeze-thaw cycles and degree of damages

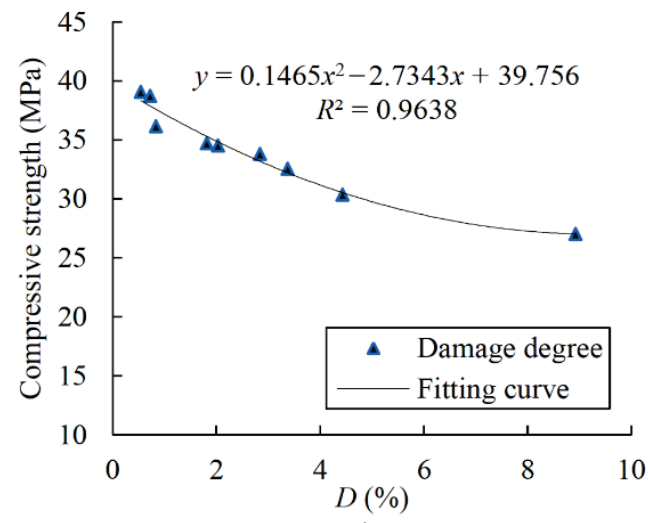

Figure 18 Relationship between degree of damages and uniaxial compressive strength

The fitting results of the degree of concrete damage and uniaxial compressive strength are illustrated in Fig. 18

$\sigma=0.1465 D^{2}-2.7343 D+39.756$

where $\sigma$ is the uniaxial compressive strength of concrete (MPa). In accordance with the fitting curve, the uniaxial compressive strength of concrete decreases gradually with the increase in the degree of damages, and the fitting degree of the trend line $\left(R^{2}\right)$ is 0.9638 .

The fitting results of the uniaxial compressive strength with the freeze-thaw cycles are illustrated in Fig. 19.

$\sigma=-0.0001 i^{2}-0.0298 i+38.794$

In accordance with the fitting curve, the uniaxial compressive strength of concrete decreases gradually with the increase in the freeze-thaw cycles, and the fitting degree of the trend line $\left(R^{2}\right)$ is 0.9561 , thereby indicating that the fitting formula can reflect the relationship between the salt freeze-thaw cycles and compressive strength.

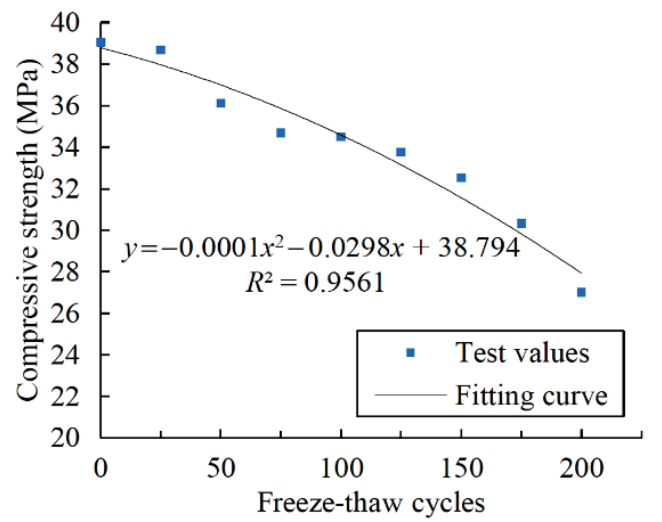

Figure 19 Relationship between salt freeze-thaw cycles and uniaxial compressive strength

\section{CONCLUSION}

A CT scanning test of concrete samples under different salt freeze-thaw cycles was conducted to study the internal damage evolutionary law of concrete in the salt freezethaw environment. The microscopic damage characteristics of concrete were investigated by analyzing the CT scanning results and $3 \mathrm{D}$ reconstruction. A concrete damage model based on aggregate volume and porosity in the salt freeze-thaw environment was constructed. Some major conclusions could be drawn:

(1) Concrete aggregate distribution and internal pores can be observed clearly from CT scan images. According to the analysis results, aggregate peeling damages are more serious at two ends of concrete samples than in the middle region in the salt freeze-thaw environment. Influenced by the $\mathrm{NaCl}$ solution, the $\mathrm{CT}$ value of concrete samples increases initially and then decreases with the increase in salt freeze-thaw cycles. Meanwhile, concrete aggregate volume increases initially and then decreases.

(2) The changes in the number of pores in concrete are closely related to the salt freeze-thaw cycles. With the increase in salt freeze-thaw, the total number of pores decreases initially and then increases. The reduction in pores in the early stage of salt freeze-thaw cycles is mainly due to two aspects. On the one hand, concrete surface peels off due to frost heaving, and the pores at the outer side decrease. On the other hand, some pores are connected given the salt freeze-thaw cycles, and the total number of pores decreases accordingly. The increased total number of pores in the late stage is due to the initiation of new pores in the loose concrete aggregate.

(3) Concrete damages in the salt freeze-salt environment are mainly caused by the changes in the porosity and volume of concrete materials. The damages caused by aggregate volume changes can be further divided into frost heaving and peeling damages. The concrete porosity changes slightly under the effect of salt freezethaw cycles, but the volume of concrete aggregate changes significantly. Therefore, the changes in aggregate volume are the main causes of intensified concrete damages and reduced uniaxial compressive strength. 
In this study, a concrete damage model based on aggregate volume and porosity was constructed using CT scan images, which can reflect the relationship between the degree of damages and the salt freeze-thaw cycles. The model has a simple form, and the parameters in the model are easy to determine. The constructed model lays a foundation for further analysis of the microscopic damage mechanism of concrete in the salt freeze-thaw environment. However, associated studies have mainly focused on the single mixing ratio of concrete. The mixing ratio of concrete can influence the mechanical properties and durability significantly. Future studies must further discuss the influences of mixing ratio on concrete performance.

\section{Acknowledgements}

The research reported in this paper was supported in part by the National Natural Science Foundation of China under Grant No.11872299 and the Natural Science Basic Research Plan in Shaanxi Province of China No.2019JQ832. The authors thank the anonymous reviewers for their constructive comments that greatly improved the quality of this manuscript.

\section{REFERENCES}

[1] Kim, J., Moon, J. H., Shim, J. W., Sim, J., Lee, H. G., \& Zi, G. (2014). Durability properties of a concrete with waste glass sludge exposed to freeze-and-thaw condition and deicing salt. Construction and building materials, 66, 398-402. https://doi.org/10.1016/j.conbuildmat.2014.05.081

[2] Song, Y. P. \& Ji, X. D. (2006). Analysis on reliability of concrete under freezing thawing action and evaluation of residual life. Journal of Hydraulic Engineering, 37(3), 259263. https://doi.org/10.13243/j.cnki.slxb.2006.03.002

[3] Hill, J., Byars, E. A., Sharp, J. H., Lynsdale, C. J., Cripps, J. C., \& Zhou, Q. (2003). An experimental study of combined acid and sulfate attack of concrete. Cement and Concrete Composites, 25(8), 997-1003. https://doi.org/10.1016/S0958-9465(03)00123-9

[4] Jiang, L., Niu, D., Yuan, L., \& Fei, Q. (2015). Durability of concrete under sulfate attack exposed to freeze-thaw cycles. Cold Regions Science and Technology, 112, 112-117. https://doi.org/10.1016/j.coldregions.2014.12.006

[5] Bogas, J. A., De Brito, J., \& Ramos, D. (2016). Freeze-thaw resistance of concrete produced with fine recycled concrete aggregates. Journal of Cleaner Production, 115, 294-306. https://doi.org/10.1016/j.jclepro.2015.12.065

[6] Colombo, I. G., Colombo, M., \& di Prisco, M. (2015). Tensile behavior of textile reinforced concrete subjected to freezing-thawing cycles in un-cracked and cracked regimes. Cement and Concrete Research, 73, 169-183. https://doi.org/10.1016/j.cemconres.2015.03.001

[7] Luo, Z., Su, B., Wang, T., Cheng, F., Wang, Y., Liu, B., \& Xie, C. (2019). Effects of Propane on the Flammability Limits and Chemical Kinetics of Methane-Air Explosions. Combustion Science and Technology, 1-17. https://doi.org/10.1080/00102202.2019.1625041

[8] Kang, P., Zhaopeng, L., Quanle, Z., Zhenyu, Z., \& Jiaqi, Z. (2019). Static and dynamic mechanical properties of granite from various burial depths. Rock Mechanics and Rock Engineering, 1-22. https://doi.org/10.1007/s00603-019-01810-y

[9] Thokchom, S., Ghosh, P., \& Ghosh, S. (2010). Performance of fly ash based geopolymer mortars in sulphate solution. Journal of Engineering Science and Technology Review, 3(1), 36-40. https://doi.org/10.25103/jestr.031.07
[10] Wilk, M. \& Magdziarz, A. (2017). An evaluation of renewable fuels microstructure after the combustion process. Journal of Power Technologies, 97(4), 265-271.

[11] Qin, L., Feng, X., Hafezi, M., Zhang, Y., Guo, J., Dong, G., \& Qin, Y. (2018). Investigating the tribological and biological performance of covalently grafted chitosan coatings on Co-Cr-Mo alloy. Tribology International, 127, 302-312. https://doi.org/10.1016/j.triboint.2018.06.018

[12] Grosse, C. U. \& Finck, F. (2006). Quantitative evaluation of fracture processes in concrete using signal-based acoustic emission techniques. Cement and Concrete Composites, 28(4), 330-336 https://doi.org/10.1016/j.cemconcomp.2006.02.006

[13] Rydberg, J., Buckwalter, K. A., Caldemeyer, K. S., et al. (2000). Multisection CT: scanning techniques and clinical applications. Radiographics, 20(6), 1787-1806. https://doi.org/10.1148/radiographics.20.6.g00nv071787

[14] Gang, W., Xiaoqiang, Z., Xinxiang, Y., Lulu, S., \& Hongyuan, Q. (2016). Establishment and Application Study of Digital Model for Coal Microstructure Based on CT Images. Journal of Engineering Science and Technology Review, 9(4), 177-184. https://doi.org/10.25103/jestr.094.25

[15] Darma, I. S., Sugiyama, T., \& Promentilla, M. A. B. (2013). Application of X-ray CT to study diffusivity in cracked concrete through the observation of tracer transport. Journal of Advanced Concrete Technology, 11(10), 266-281. https://doi.org/10.3151/jact.11.266

[16] Vicente, M. A., Ruiz, G., Gonzalez, D. C., Minguez, J., Tarifa, M., \& Zhang, X. (2018). CT-Scan study of crack patterns of fiber-reinforced concrete loaded monotonically and under low-cycle fatigue. International Journal of Fatigue, 114, 138-147. https://doi.org/10.1016/j.jfatigue.2018.05.011

[17] Sicat, E., Gong, F., Ueda, T., \& Zhang, D. (2014). Experimental investigation of the deformational behavior of the interfacial transition zone (ITZ) in concrete during freezing and thawing cycles. Construction and Building Materials, 65, 122-131. https://doi.org/10.1016/j.conbuildmat.2014.04.035

[18] Gong, F., Sicat, E., Zhang, D., \& Ueda, T. (2015). Stress analysis for concrete materials under multiple freeze-thaw cycles. Journal of Advanced Concrete Technology, 13(3), 124-134. https://doi.org/10.3151/jact.13.124

[19] Hasan, M., Ueda, T., \& Sato, Y. (2008). Stress-strain relationship of frost-damaged concrete subjected to fatigue loading. Journal of Materials in Civil Engineering, 20(1), 37-45. https://doi.org/10.1061/(ASCE)0899-1561(2008)20:1(37)

[20] Nili, M., Azarioon, A., \& Hosseinian, S. M. (2017). Novel internal-deterioration model of concrete exposed to freezethaw cycles. Journal of Materials in Civil Engineering, 29(9), 04017132. https://doi.org/10.1061/(ASCE)MT.1943-5533.0001978

[21] Li, B., Yin, H., Mao, X., Li, Y., Zhang, L., Liu, R., \& Qiu, P. (2016). Macroscopic and microscopic fracture features of concrete used in coal mine under chlorine salt erosion. International Journal of Mining Science and Technology, 26(3), 455-459. https://doi.org/10.1016/j.jmst.2016.02.014

[22] Farnam, Y., Wiese, A., Bentz, D., Davis, J., \& Weiss, J. (2015). Damage development in cementitious materials exposed to magnesium chloride deicing salt. Construction and Building Materials, 93, 384-392. https://doi.org/10.1016/j.conbuildmat.2015.06.004

[23] Kuosa, H., Ferreira, R. M., Holt, E., Leivo, M., \& Vesikari, E. (2014). Effect of coupled deterioration by freeze-thaw, carbonation and chlorides on concrete service life. Cement and Concrete Composites, 47, 32-40. https://doi.org/10.1016/j.cemconcomp.2013.10.008

[24] Wang, Y., An, M. Z., Yu, Z. R., Han, S., \& Ji, W. Y. (2017). Durability of reactive powder concrete under chloride-salt freeze-thaw cycling. Materials and Structures, 50(1), 18. 
https://doi.org/10.1617/s11527-016-0878-5

[25] Skripkiūnas, G., Nagrockienė, D., Girskas, G., Vaičienė, M., \& Baranauskaite, E. (2013). The cement type effect on freeze-thaw and deicing salt resistance of concrete. Procedia Engineering, 57, 1045-1051. https://doi.org/10.1016/j.proeng.2013.04.132

[26] Ren, W., Yang, Z., Sharma, R., Zhang, C. H., \& Withers, P. J. (2015). Two-dimensional X-ray CT image based meso-scale fracture modelling of concrete. Engineering Fracture Mechanics, 133, 24-39. https://doi.org/10.1016/j.engfracmech.2014.10.016

[27] Henry, M., Darma, I. S., \& Sugiyama, T. (2014). Analysis of the effect of heating and re-curing on the microstructure of high-strength concrete using X-ray CT. Construction and Building Materials, 67, 37-46. https://doi.org/10.1016/j.conbuildmat.2013.11.007

[28] Suzuki, T., Ogata, H., Takada, R., Aoki, M., \& Ohtsu, M. (2010). Use of acoustic emission and X-ray computed tomography for damage evaluation of freeze-thawed concrete. Construction and Building Materials, 24(12), 2347-2352. https://doi.org/10.1016/j.conbuildmat.2010.05.005

[29] Tian, W., Wang, Z., \& Han, N. (2019). Study of Mesodamage Mechanism of Concrete under Sulfate Attack. Journal of Disaster Prevention and Mitigation Engineering, 39(1), 16-22. https://doi.org/10.13409/j.cnki.jdpme.2019.01.003

[30] National Standard of the People's Republic of China. (2009). GB/T50082-2009 Standard for Test Methods of Long-Term Performance and Durability of Ordinary Concrete. Beijing: China Architecture and Building Press.

[31] Li, J. J., Han, Y., \& Wamg, L. M. (2008). Study on the method of graphite density uniformity inspection based on x-ray ICT. Nondestructive Testing, 3, 163-164. https://doi.org/10.3969/j.issn.1000-6656.2008.03.008

[32] Akin, S. \& Kovscek, A. R. (2003). Computed tomography in petroleum engineering research. Geological Society, London Special Publications, 215(1), 23-38. https://doi.org/10.1144/GSL.SP.2003.215.01.03

\section{Yongxin CHE}

School of Architecture and Civil Engineering, X'an University of Science and Technology, 58 Yanta Road, Yanta district, Xi'an, China E-mail: cheyongxin94@163.com

\section{Jiaxing CHEN}

School of Architecture and Civil Engineering X'an University of Science and Technology, 58 Yanta Road, Yanta district, Xi'an, China E-mail: renxingchen96@163.com

\section{Contact information:}

\section{Shaojie CHEN}

(Corresponding author)

School of Architecture and Civil Engineering,

X'an University of Science and Technology,

58 Yanta Road, Yanta district, Xi'an, China

E-mail: csj@xust.edu.cn

Jianxi REN, PhD, Professor

School of Architecture and Civil Engineering Xi'an University of Science and Technology,

58 Yanta Road, Yanta district, Xi'an, China

E-mail: renjianxi1968@163.com

Yongjun SONG, PhD, Associate Professor School of Architecture and Civil Engineering Xi'an University of Science and Technology, 58 Yanta Road, Yanta district, Xi'an, China E-mail: songyj79@xust.edu.cn

\section{Qiang LI, PhD}

School of Architecture and Civil Engineering, Xi'an University of Science and Technology, 58 Yanta Road, Yanta district, Xi'an, China E-mail: 47961419@qq.com

\section{Jielong SUN, PhD}

School of Architecture Engineering,

Yan'an University,

580 Shengdi Road, Baota district, Yan'an, China

E-mail: sunjielong@126.com 